\title{
Aspectos agronômicos da mamoneira irrigada com efluentes tratados
}

\section{Agronomic aspects of castor bean irrigated with treated effluents}

Data de entrada: $14 / 03 / 2016$

Data de aprovação: $25 / 10 / 2017$

Maria do Socorro Ribeiro Hortegal Filha*/ Germário Marcos Araújo/ Francisco José Carvalho Moreira/ Luis Gonzaga Pinheiro Neto

DOI:10.4322/dae.2018.029

\section{Resumo}

O objetivo deste trabalho foi avaliar o crescimento da mamoneira (Ricinus communis L.) irrigada com dois tipos de efluentes tratados. O delineamento estatístico foi o de bloco ao acaso, em 4 tratamentos e 6 repetições, sendo: T1 - irrigação com água em solo sem adubo; T2 - irrigação com água em solo com adubo; T3 - irrigação com efluente da lagoa em solo sem adubo; e T4 - irrigação com efluente tratado da lagoa em solo sem adubo. Entre os tratamentos, foi avaliado o efeito dos tipos de água sob o crescimento da mamona por meio das variáveis: Altura Caulinar (AC) em cm; Diâmetro Caulinar (DC) em mm, número de foIhas (NF) e matéria seca da parte aérea. O T3 apresentou maiores valores médios: 43,1 cm; 24,1 mm e 16,7 unidades para AC, DC e NF, respectivamente, seguido do T4 com 38,3 cm para AC; $23 \mathrm{~mm}$ para DC e 14,3 unidades para NF, mostrando que os nutrientes presentes nas águas de irrigação dos T3 e T4 devem ter influenciado de maneira significativa. Para matéria seca, o T3 também foi o tratamento de melhor desempenho, concluindo que efluentes tratados podem ser reusados em cultivo de mamonas com bom desempenho.

Palavras-chave: Reúso. Mamona. Irrigação.

\section{Abstract}

The objective of this work was to evaluate the growth of the castor bean (Ricinus communis L.) irrigated with two types of treated effluents. The statistical design was a randomized block design in 4 treatments and 6 replications: T1: irrigation with water in soil without fertilizer; T2- irrigation with water in soil with fertilizer; T3- irrigation with pond effluent in soil without fertilizer and T4 irrigation with post-treated pond effluent in soil without fertilizer. Among the treatments, the effect of the water types under the growth of the castor bean was evaluated by means of the following variables: Height Caulinar (AC) in cm; Diameter Caulinar (DC) in $\mathrm{mm}$, number of leaves (NF) and shoot dry matter. T3 had higher mean values $43.1 \mathrm{~cm} ; 24.1 \mathrm{~mm}$ and 16.7 units for AC, DC and NF, respectively, followed by T4 with $38.3 \mathrm{~cm}$ for AC; $23 \mathrm{~mm}$ for DC and 14.3 for NF, showing that the nutrients present in the irrigation waters of T3 and T4 must have had a significant influence. For dry matter, T3 was also the best performance treatment, concluding that treated effluents can be reused in castor bean cultivation with good performance. Keywords: Reuse. Castor bean. Irrigation

\footnotetext{
Maria do Socorro Ribeiro Hortegal Filha - Doutora em Engenharia Civil (Saneamento Ambiental) pela Universidade Federal do Ceará (UFC).Mestre em Engenharia Civil (Saneamento Ambiental) pela UFC. Professora do Instituto Federal de Educação, Ciência e Tecnologia do Ceará (IFCE). Germário Marcos Araújo - Doutor em Engenharia Civil (Saneamento Ambiental) pela UFC. Mestre em Engenharia Sanitária pela Universidade Federal do Rio Grande do Norte. Professor do IFCE.

Francisco José Carvalho Moreira - Doutorando em Biotecnologia (Recursos Naturais) na Renorbio. Mestre em Agronomia/Fitotecnia/ Fitossanidade pela UFC.Professor do IFCE.

Luis Gonzaga Pinheiro Neto - Doutor em Fitotecnia pela Universidade Federal Rural do Semi-Árido. Mestrado em Engenharia Agrícola pela UFC.Professor do IFCE.

*Endereço para correspondência: Rua Professor Vicente Silveira, 1031 - Apto 301A - Vila União - Fortaleza - CE CEP: 60410-670. E-mail: socorrohortegalaifce.edu.br; socorrohortegal7agmail.com.
} 


\section{INTRODUÇÃO}

Apesar de o Brasil ser privilegiado pela natureza, com grandes quantidades de corpos hídricos, o país enfrenta uma grave crise hídrica, antes enfrentada apenas por algumas regiões. Segundo Silva (2015) e Souza et al. (2015), vários fatores contribuíram para esse panorama, entre eles o crescente desmatamento da região amazônica, a falta de investimentos e planejamento por parte dos governantes, a distribuição geográfica dos recursos hídricos, o consumo per capita crescente como consequência do aumento acelerado da população e o desperdício por parte dos consumidores, entre outros. Segundo Telles e Costa (2010), em muitas regiões os recursos hídricos são insuficientes para atender às demandas elevadas; diante disso há conflitos de usos e restrições de consumo que afetam o desenvolvimento econômico e a qualidade de vida.

A água no planeta é sempre a mesma, uma vez que o ciclo hidrológico sempre se repetirá, garantindo água em quantidade. No entanto, o que pode ser alterada é a sua qualidade. Lima (2012) comenta que a natureza consegue recuperar a degradação de seus recursos, inclusive aquelas geradas pelo homem, mas a demanda atual é tão grande e rápida que a natureza não consegue acompanhar o ritmo que a economia exige de seus recursos, levando-os à alteração das suas características qualitativas.

A elevação da demanda de água implica diretamente no aumento da geração dos esgotos, que, lançados em corpos receptores, sem tratamento, aumentam os impactos ambientais negativos, tornando-os inapropriados a diferentes usos. Como forma de minimizar tais impactos, faz-se necessário o uso de tecnologias de tratamento dos esgotos, e, entre várias, estão as lagoas de estabilização, que se bem projetadas e operadas chegam a reduzir consideravelmente a carga orgânica, minimizando assim os impactos negativos. Silva et al., (2014) menciona que os esgo- tos podem ser considerados água de qualidade inferior, mas devem prioritariamente passar por tratamentos para posteriormente reusá-los em várias atividades, como agricultura, resfriamento de maquinários, construção civil, entre outras atividades. A reutilização das águas tratadas, principalmente na agricultura, pode melhorar a qualidade de vida do produtor e diminuir o uso de água disponibilizando uma água de melhor qualidade para a população.

De toda a água captada no país, as atividades agrícolas consomem cerca de $70 \%$, seguidas pela indústria, com cerca de $22 \%$, e a utilização doméstica, com cerca de $8 \%$, de modo que o reúso de efluentes tratados deve ser incentivado, e a implementação de programa dessa natureza pode ser difundida em toda região onde a escassez de água é uma realidade, principalmente em áreas agrícolas de culturas que resistem à seca e há água de qualidade inferior, como por exemplo a mamona (MMA, 2014).

A mamoneira (Ricinus communis L.) é uma planta rústica, heliófita, pertencente à família Euphorbiaceae. Também conhecida como carrapateira, ricinio, palma christi e castor bean, é uma cultura resistente à seca e encontrada em diversas regiões do país. Sua produção é praticada normalmente por pequenos produtores, tornando-se uma alternativa de renda para eles. Em geral é consorciada com outras culturas; desse modo utiliza-se pouco agrotóxico, e se adapta perfeitamente às regiões semiáridas do Nordeste, (CARVALHO, 2005). No seu cultivo é utilizado um baixo nível de tecnologia na maioria dos plantios. Seu cultivo principal é na agricultura de sequeiro, limitando a sua produção, trazendo vários riscos para os produtores e, por conseguinte, diminuindo sua renda, pois ele depende somente da chuva para irrigar a cultura.

O produto principal é o óleo extraído das sementes, conhecido no Brasil como óleo de ríci- 
no ou internacionalmente como castor oil. Esse óleo processado tem inúmeras aplicações, que incluem o uso medicinal e cosmético, a fabricação de plásticos, de lubrificantes e de biodiesel. É também utilizado na produção de fibra ótica, vidro à prova de balas e próteses ósseas. Além disso, é indispensável para impedir o congelamento de combustíveis e lubrificantes de aviões e foguetes espaciais a baixíssimas temperaturas (ANJOS e SILVA, et. al., 2007). A utilização da mamoneira para a produção de biodiesel na região Nordeste é uma nova tentativa de inclusão social por meio da agricultura familiar, melhorando a condição de vida do homem do campo, oferecendo mais uma fonte de renda para ele.

Os parâmetros de crescimento das plantas são bastante estudados, pois permitem uma primeira análise das estimativas de produção e não necessitam de equipamentos sofisticados. Segundo Magalhães (1979), a análise de crescimento da planta consiste no método que descreve as condições morfofisiológicas da planta em diferentes intervalos de tempo para quantificar o desenvolvimento de um vegetal. Para Machado et. al. (1982), as principais análises de crescimento são obtidas a certos intervalos de tempo durante a estação de crescimento da cultura. As variações da quantidade de biomassa e da área foliar são utilizadas, com o tempo, na estimativa de vários índices fisiológicos.

Diante do que foi exposto, o presente trabalho objetivou avaliar as características de crescimento da mamoneira produzida com o uso de efluentes tratados por lagoas de estabilização da cidade de Sobral, no Ceará.

\section{MATERIAIS E MÉTODOS}

O experimento com a cultura da mamona irrigada com efluente doméstico tratado, em escala experimental, foi realizado de agosto de 2012 a janeiro 2013, e foi instalado dentro das depen- dências do IFCE campus Sobral, com coordenadas geográficas do município de $4^{\circ} 13^{\prime}$ latitude Sul e $42^{\circ} 46^{\prime}$ longitude oeste de Greenwich, distando $238 \mathrm{~km}$ Fortaleza, a uma altitude de $70 \mathrm{~m}$ acima do nível do mar e o acesso se dá pela BR 222, que liga o Ceará ao Piauí. O clima é o tropical, com estação seca e pela classificação climática de Köppen-Geiger é Aw (IBGE, 2010).

A cidade de Sobral possui uma população de aproximadamente 190.724 habitantes, gerando uma vazão média de esgotos de 264,90 L.s ${ }^{-1}$, que são tratados por seis Estações de Tratamento de Esgoto (ETE), todos por lagoas de estabilização. A ETE do Padre Palhano, escolhida para este estudo, recebe contribuição de 2177 ligações. É constituída pelos níveis preliminar (TP) composto de caixa de areia, grade e Calha Parshall, secundário: pela lagoa facultativa (LF) e terciário: com duas lagoas de maturação (LMI) e (LMII). Após passar pela última lagoa, o efluente considerado tratado é lançado no rio Acaraú, que passa nas proximidades da ETE. A vazão média afluente a ETE é $0,03 \mathrm{~m}^{3} \cdot \mathrm{s}^{-1}$ e a tabela 1 apresenta as características físicas de cada lagoa.

Tabela 1: Características físicas da ETE Padre Palhano

\begin{tabular}{|c|c|c|c|c|c|}
\hline Lagoa & $\begin{array}{c}\text { Largura } \\
\mathbf{( m )}\end{array}$ & $\begin{array}{c}\text { Comprimento } \\
\mathbf{( m )}\end{array}$ & $\begin{array}{c}\text { Área } \\
\left(\mathbf{( m}^{\mathbf{2}} \mathbf{m}\right.\end{array}$ & $\begin{array}{c}\text { Volume } \\
\left(\mathbf{( m}^{\mathbf{3}} \mathbf{)}\right.\end{array}$ & $\begin{array}{c}\mathbf{1 / 2} \\
\mathbf{H}\end{array}$ \\
\hline Facultativa & 126,2 & 171,6 & $21.655,9$ & $49.808,57$ & 2,3 \\
\hline Maturação I & 47,3 & 171,6 & $8.116,7$ & $12.175,1$ & 1,5 \\
\hline Maturação II & 45,1 & 171,6 & $7.739,2$ & $12.382,7$ & 1,6 \\
\hline
\end{tabular}

Durante a pesquisa, as coletas das amostras do efluente foram realizadas na última lagoa de maturação da ETE Padre Palhano, com frequência de três vezes por semana, sempre pela manhã, no período de agosto a dezembro de 2012, para a irrigação da cultura da mamona. Essas amostras foram acondicionadas em vasilhames plásticos de $5 \mathrm{~L}$ e mantidas sob refrigeração até horas antes da irrigação, para retardar o metabolismo 
dos microrganismos, como forma de tentar manter as características do efluente.

Paralelamente, numa frequência quinzenal, também foram realizadas coletas de amostras, na mesma lagoa, para análises dos parâmetros físicos, químicos e biológicos (TABELA 2). Todos os procedimentos de preparo, volume, acondicionamento e transporte das amostras seguiram as recomendações da APHA, 2005.

Tabela 2: Características dos efluentes utilizados na pesquisa

\begin{tabular}{|c|c|c|c|c|}
\hline $\begin{array}{c}\text { PARÂMETRO } \\
\begin{array}{c}\text { Condutividade } \\
\text { Elétrica }\end{array}\end{array}$ & METODOLOGIA & UNIDADE & EFLUENTE 1 & EFLUENTE 2 \\
\hline Sódio & Potenciométrico & 1183,4 & 1183,4 \\
\hline Potássio & Fotométrico de Chama & $\mathrm{mg} / \mathrm{L}$ & 295,6 & 295,6 \\
\hline RAS & RICHARDS, 1954 & $\mathrm{mg} / \mathrm{L}$ & 30,1 & 30,1 \\
\hline pH & Potenciométrico & $\mathrm{mg} / \mathrm{L}$ & 50,5 & 29,0 \\
\hline Temp. ${ }^{\circ} \mathrm{C}$ & Filamento de Mercúrio & & 7,8 & 7,8 \\
\hline Cloretos & Argentométrico & ${ }^{\circ} \mathrm{C}$ & 27,9 & 27,9 \\
\hline Dureza Total & Titulométrico do EDTA & $\mathrm{mg} / \mathrm{L}$ & 177,1 & 179,9 \\
\hline Cálcio & Titulométrico do EDTA & $\mathrm{mg} / \mathrm{L}$ & 219,5 & 219,5 \\
\hline Magnésio & Titulométrico do EDTA & $\mathrm{mg} / \mathrm{L}$ & 52,8 & 48,8 \\
\hline Amônia & Nesslerização Direta & $\mathrm{mg} / \mathrm{L}$ & 21,3 & 21,3 \\
\hline Nitrato & Salicilato de Sódio & $\mathrm{mg} / \mathrm{L}$ & 34,5 & 34,5 \\
\hline Fósforo & $\begin{array}{c}\text { Espectrofotométrico do Ácido Ascórbico com } \\
\text { pré-digestão com Persulfato de Amônia }\end{array}$ & $\mathrm{mg} / \mathrm{L}$ & 3,5 & 0,3 \\
\hline Ortofosfato & Espectrofotométrico do Ácido Ascórbico & $\mathrm{mg} / \mathrm{L}$ & 1,9 & 3,5 \\
\hline DQ:O & Refluxação Fechada & $\mathrm{mg} / \mathrm{L}$ & 292,1 & 29,3 \\
\hline
\end{tabular}

Fonte: APHA (2005)

As mudas da mamoneira cultivar BRS Nordestina foram produzidas em bandejas de isopor, com 128 células, sendo utilizado como substrato o solo da região, tendo como classificação física franco-arenoso. Após 20 dias da semeadura, as mudas foram transplantadas para os vasos. Paralelamente à germinação, foi determinada em laboratório do IFCE Campus Sobral a capacidade de campo, utilizando o método de RICHARDS (1949) para determinar a quantidade de água necessária para o trabalho. Em cada vaso foi utilizado cerca de 1,8 $\mathrm{L}$ de água diária. As plantas daninhas foram controladas manualmente, e houve aplicação de produtos fitossanitários, quando necessário, durante todo experimento.

Para avaliar o efeito do tratamento de efluentes na irrigação da mamoneira, foi instalado um experimento no delineamento experimental de blocos ao acaso com 4 tratamentos: T1 - irrigação com água em solo (franco-arenoso) sem adubo; T2 - irrigação com água em solo (franco-arenoso) com adubo ( $1 / 3$ de esterco de gado); T3 - irrigação com efluente 1 a em solo (franco-arenoso) sem adubo e T4 - irrigação com efluente 2 em solo (franco-arenoso) sem adubo, com 6 repetições, totalizando 24 unidades experimentais.

O efluente 2 é considerado um polimento do efluente final das lagoas de maturação e foi obtido a partir do tratamento físico-químico de coagulação-floculação-sedimentação com o auxílio do sulfato de alumínio, realizados em baldes de polietileno. A água utilizada no T1 foi coletada na torneira do IFCE campus Sobral, que fica próximo ao local do experimento. Essa água é oriunda do sistema de tratamento público para o abastecimento da cidade e também é utilizada para irrigar as áreas verdes do campus. 
O experimento foi realizado em vasos, e durante todo o período a irrigação foi realizada manualmente, com o auxílio de um regador plástico. Vale ressaltar que foram utilizados os devidos equipamentos de proteção individual, visando à proteção do manipulador dos regadores. Devido ao presente trabalho enaltecer aspectos puramente agronômicos e também ao fato de a cultura estudada não ser de consumo direto, os parâmetros coliformes termotolerantes e ovos de helmintos não foram levados em consideração neste estudo. Ressalta-se que em sistemas de lagoas de estabilização, devido ao elevado tempo de detenção hidráulica, são eficientes na remoção de ovos de nematódeos intestinais e coliformes termotolerantes.

O experimento foi irrigado em duas etapas, sendo $50 \%$ da água recomendada pela manhã e $50 \%$ no turno da tarde, durante 112 dias. Apesar de a rega ter sido manual, não se deve descartar a possibilidade de contaminação sanitária por parte dos responsáveis pela irrigação. Para avaliar esse risco, porém, seria necessária a determinação das variáveis bacteriológicas, e estas não foram executada neste trabaIho. Entretanto, a literatura comenta que águas provenientes de lagoas de maturação e de polimento, em sistemas de tratamento bem manejados, apresentam potencial para serem utilizadas na irrigação da maioria das culturas, evitando contaminação aos trabalhadores, aos animais e consumidores.

A carga de nutrientes aplicados nos vasos, durante o período de estudo, na forma de efluentes foi disposta na Tabela 3.

Tabela 3: Carga nutricional aplicada nos vasos dos tratamentos.

\begin{tabular}{|c|c|}
\hline Nutriente & $\begin{array}{c}\text { Efluente 1 e 2 } \\
\text { (mg. vaso-1) }\end{array}$ \\
\hline Nitrogênio & 3897,6 \\
\hline Fósforo & 6048 \\
\hline Potássio & 60,48 \\
\hline
\end{tabular}

Fonte: Próprio do autor
A caracterização do crescimento da cultura foi realizada semanalmente de agosto de 2012 a janeiro 2013, utilizando-se o método da análise clássica não destrutiva, seguindo a metodologia utilizada SILVA et al. (2014). Os parâmetros analisados foram: Altura da planta (AP) em cm; Diâmetro Caulinar (DC) em mm e contagem do número de folhas (NF). Para isso foram necessários os seguintes equipamentos: trena graduada para determinar a altura caulinar e paquímetro digital para verificar o diâmetro; a contagem das folhas foi realizada manualmente. Para a determinação da matéria seca da planta foi utilizado o procedimento de análises destrutivas. Após o final do experimento, as plantas foram retiradas dos vasos e separaram-se o caule, as folhas e as raízes. Em seguida, as partes das plantas de mamoneira foram submetidas à secagem numa estufa a temperatura de $65^{\circ} \mathrm{C}$, por 48 horas, até a obtenção do peso constante da massa seca do caule (MSC), das folhas (MSF) e da raiz (MSR), que foram determinadas com auxílio de uma balança digital.

Os dados obtidos na pesquisa foram submetidos a análises de variância, quando significativa pelo teste de F. Posteriormente foram submetidos ao teste de Tukey ao nível de $1 \%$ e $5 \%$ de probabilidade. Para as análises de crescimento não destrutivas, os dados coletados foram submetidos à análise de regressão, buscando-se ajustar equações com significados biológicos. $\mathrm{Na}$ análise de regressão, as equações de regressão que melhor se ajustaram aos dados foram escolhidas com base na significância dos coeficientes de regressão a $1 \%$ e $5 \%$ de probabilidade pelo teste $\mathrm{F}$ e no maior coeficiente de determinação (R2). Para esse estudo foi utilizado o programa estatístico Assistat 7.7 Beta, (Silva e Azevedo, 2009). 


\section{RESULTADOS E DISCUSSÃO}

\subsection{Caracterização do Efluente da Lagoa de Maturação do Padre Palhano}

O sulfato de alumínio foi utilizado para promover um melhoramento no efluente final da lagoa de maturação da ETE Padre Palhano, considerando assim um polimento do efluente, e proporcionou no efluente 2 valores de $\mathrm{pH}$ e turbidez ideal para crescimento de uma planta. A remoção da turbidez está diretamente relacionada com a remoção de sólidos suspensos, as algas, que representa em sua maioria nas lagoas de maturação. Segundo a resolução Conama 430 de 2011, o limite de turbidez permitido é de até 100 UNT para lançamento em corpo d'água. Como a turbidez do efluente tratado da lagoa de maturação do Pe. Palhano foi em média de 134,6 UNT, com melhoramento do efluente, a turbidez reduziu para 3,78 UNT, não sendo ideal para ser reutilizado, pois pode-se dizer que a baixa turbidez está associada a baixas concentrações de nutrientes e assim não sendo satisfatória para que houvesse um bom crescimento da mamona. Diante disso, foi feita uma adição de sulfato de alumínio de modo que se obtivesse a turbidez de 100 UNT, garantindo as quantidades de nutrientes para cultura.

Os valores médios de temperatura nos Efluentes 1 e 2 foram iguais a $27,9^{\circ} \mathrm{C}$. Esse valor encontra-se na faixa ideal para as atividades metabólicas dos organismos responsáveis pela degradação da matéria orgânica. Em países tropicais e subtropicais, a maior parte das bactérias contidas na água é mais eficiente para degradar a matéria orgânica quando a temperatura do ambiente aquático está entre $20^{\circ} \mathrm{C}$ e $45^{\circ} \mathrm{C}$, e para reúso na agricultura a faixa fica entorno de $20^{\circ} \mathrm{C}$ a $30^{\circ} \mathrm{C}$. (EMBRAPA, 2008; MARA, 1998)

$\mathrm{O}$ valor de 7,8 do $\mathrm{pH}$ médio foi constante durante o período de estudado, tanto para o Efluente 1 como para o Efluente 2. Esses valores se encontram dentro da faixa de lançamento de esgotos tratados, como recomenda o Conama 430/2011.
$\mathrm{O} \mathrm{pH}$ no efluente final de uma ETE deve estar dentro da faixa de 5,0 - 9,0, estando dentro da faixa recomendada. Além disso, segundo Ayres (1991), essa é a faixa ideal para reúso na agricultura.

A concentração de matéria orgânica nos esgotos brutos domésticos é usualmente estimada a partir da medida indireta, por meio das análises de DBO. Neste trabalho, essa variável foi obtida por meio de um equacionamento que relaciona os valores de DQO e DBO. Os valores dessa relação variaram entre 2,5 a 3,0 nos efluentes tratados. $O$ valor de DBO obtido pelo equacionamento foi de $104,3 \mathrm{mg} \cdot \mathrm{L}^{-1}$, para os dois tipos de efluente, uma vez que o valor da DOQO para ambos os efluentes foi $292,1 \mathrm{mg} . \mathrm{L}^{-1}$, como disposto na Tabela 2. Esses valores (DBO e DQO) encontram-se ligeiramente superiores ao padrão de lançamento, segundo a Portaria 154 da Semace. No entanto, o valor recomendado de DBO em efluentes tratados é inferior a $100 \mathrm{mg} \cdot \mathrm{L}^{-1}$ quando se deseja reusar na agricultura, podendo dizer que neste estudo o valor encontra-se ligeiramente acima do recomendado segundo NUVOLARI (2008). No entanto, apesar da DBO ligeiramente elevada, o que poderia limitar a absorção da água pela planta, os resultados obtidos nos aspectos agronômicos da mamoeira evidenciam que não foi demonstrada a limitação da absorção da água no período estudado.

Os valores dispostos na Tabela 2, as concentrações de fósforo total foram de $3,5 \mathrm{mg} \cdot \mathrm{L}^{-1}$ e de $1,9 \mathrm{mg} \cdot \mathrm{L}^{-1}$ para o ortofosfato, para os dois tipos de efluentes, mostrando que o Efluente 2, que recebeu o coagulante, não teve alteração para essas duas variáveis. No entanto, quando se observam as formas de fósforo, o fósforo total foi superior ao ortofosfato, mostrando que os micro-organismos, nos seus processos metabólicos, podem ter assimilado os nutrientes. De acordo com Von Sperling (1996), o fósforo total deve apresentar concentrações variando de 5 a $20 \mathrm{mg}$. $\mathrm{L}^{-1}$ para efluente tratado, estando o valor encontrado neste estudo abaixo do citado. O fósforo é um nutriente encontrado nas 
águas residuárias; no geral, é benéfico para as colheitas, porém em excesso pode causar um efeito negativo sobre as plantas e no solo, podendo reduzir a disponibilidade de nutrientes como o $\mathrm{Cu}$, Fe e Zn (EPHA, 1995; FEIGIN, 1991). O ortofosfato é diretamente disponível para o metabolismo biológico sem necessidade de conversões para a degradação esgotos (VON SPERLING, 2005). Segundo FAO (1973), águas de reúso destinadas à irrigação devem apresentar valores variando de 0 a $26 \mathrm{mg} \mathrm{PO} 4 \mathrm{~L}-1$ mostrando que os efluentes encontram-se dentro da faixa recomendada.

Nas águas residuárias não tratadas, as concentrações de amônia são elevadas, aproximadamente $30 \mathrm{mg}^{-L^{-1}}$ (APHA, 2005). Neste estudo, o valor médio da concentração de amônia foi de $34,5 \mathrm{mgNH}_{3} \cdot \mathrm{L}^{-1}$, para os tipos de efluentes (1 e 2), como disposto na Tabela 3, revelando que é semelhante às concentrações de esgoto bruto. Em contrapartida, os valores de nitrato foram iguais a 0,3 $\mathrm{mg} \mathrm{NO}_{3}$. $\mathrm{L}^{-1}$ para os dois efluentes, também demonstrado na Tabela 3. Analisando os dois resultados, pode-se ver claramente que nessa lagoa as concentrações de amônia e nitrato são inversamente proporcionais; normalmente em lagoas de estabilização a amônia possui elevadas concentrações no esgoto bruto e no efluente final as concentrações são menores, mostrando haver conversão, uma vez que matéria orgânica, nutrientes e oxigênio estão disponíveis para as bactérias responsáveis pela nitrificação, que desempenha-se de forma eficiente. Entretanto, pode-se dizer que houve baixa atividade de nitrificação, pois os valores de amônia no efluente final estão próximo ao do esgoto bruto. Para o nitrato, o processo é inverso, podendo encontrar elevadas concentrações no efluente final, porém os baixos valores de nitrato podem estar associados à assimilação pelos microrganismos, uma vez que essa forma de nitrogênio é a preferida.

Segundo Ayres e Westcot, (1999), águas destinadas à irrigação devem apresentar concentrações de amônia variando de 0 a $5 \mathrm{mg} \cdot \mathrm{L}^{-1}$, e para o nitrato, as recomendações são valores que variam de 0-10 mg. L-1. Blum (2003) revela que os valores de nitrato encontrados estão ligeiramente acima do limite inferior e que podem ser reusados em cultivo de culturas.

Uma das maiores preocupações do uso de esgoto doméstico tratado em irrigação é o risco de salinização do solo, que foi avaliado em função dos parâmetros condutividade elétrica e razão de adsorção de sódio (RAS) (SANTOS, 2004).

Os riscos de salinidade, quanto à condutividade elétrica, para o solo e cultura, proporcionados pela água de irrigação, podem ser avaliados. No decorrer do estudo, o valor da condutividade elétrica foi de $1,18 \mathrm{dS} / \mathrm{m}$, estando inseridos os efluentes na Classe 3, implicando salinidade alta. Nessa classe as águas não podem ser utilizadas em áreas que apresentem restrições quanto à drenagem; no entanto, o solo utilizado nos vasos onde foi cultivada a mamona possuía classificação física de franco-arenoso, com boa drenagem, não necessitando de cuidados especiais em relação à drenagem (BLUM, 2003). Além disso, AYRES (1991) afirma que solos com alta salinidade podem prejudicar o crescimento de cultura. A determinação do RAS considera os problemas de infiltração como resultado do excesso do cálcio em relação ao magnésio. Essa variável foi obtida pelo equacionamento, e os resultados foram 50,5 e 29,9 mg. $\mathrm{L}^{-1}$ nos Efluentes 1 e Efluentes 2 respectivamente. Segundo Blum (2003), para valores de RAS superiores a 9 ou 10 $\mathrm{mg} \cdot \mathrm{L}^{-1}$, em água destinada à irrigação é necessária uma verificação e alguns cuidados prévios com relação à possibilidade de "inchamento" do solo, caso seja argiloso. Neste estudo os valores encontrados nos efluentes foram superiores aos recomendados pelo autor supracitado, porém a cultura suportou, visto que houve um bom crescimento. Além disso, o solo utilizado possuía pouca quantidade de argila, não chegando a influenciar na infiltração. 


\subsection{Aspectos Agronômicos da Mamoneira}

Com pode ser visualizado na Tabela 4, houve diferença significativa entre os tratamentos T1, T2, T3 e T4, jarros irrigados com água em solo sem adubo, irrigados com água em solo com adubo, irrigados com efluente da lagoa em solo sem adubo e irrigados com efluente pós-tratado em solo sem adubo, respectivamente, de acordo com o teste de Tukey.

Tabela 4: Valores médios da Altura da Planta (AP), Diâmetro do caule (DC) e Número de folhas (NF).

\begin{tabular}{|c|c|c|c|}
\hline Tratamento & $\begin{array}{c}\text { Altura da } \\
\text { Planta (cm) }\end{array}$ & $\begin{array}{c}\text { Diâmetro do } \\
\text { Caule } \mathbf{( m m}\end{array}$ & $\mathbf{N}^{\circ}$ de Folhas \\
\hline T1 & $17,9 \mathrm{~d}$ & $9,2 \mathrm{c}$ & $6,5 \mathrm{c}$ \\
\hline T2 & $24,3 \mathrm{c}$ & $13,6 \mathrm{~b}$ & $7,4 \mathrm{c}$ \\
\hline T3 & $43,1 \mathrm{a}$ & $24,1 \mathrm{a}$ & $16,7 \mathrm{a}$ \\
\hline T4 & $38,3 \mathrm{~b}$ & $23,0 \mathrm{a}$ & $14,3 \mathrm{~b}$ \\
\hline CV(\%) & 21,07 & 24,43 & 33,12 \\
\hline DMS & 2,43 & 1,64 & 1,392 \\
\hline
\end{tabular}

A coleta de dados, semanal, proporcionou valores médios apresentados na Tabela 3. Pode-se observar que entre quatro tratamentos o T3 (efluente sem tratamento) foi o superior, ou seja, o efluente das lagoas de estabilização do Padre Palhano foi melhor para promover o crescimento da mamoneira do que a água de abastecimento, para as três variáveis em estudo, AC, DC e NF, 43,1 cm; 24,1 mm e 16,7 unidades, respectivamente.

Verifica-se quanto AP, em ordem de importância de tratamento, foram: T3, T4, T2 e T1, sendo este último irrigado com água da rede pública sem nenhum tipo de adubo, apresentando o valor de $17,9 \mathrm{~cm}$, mostrando não haver um bom desenvolvimento da mamoneira, pois esta AP foi a menor durante o período de estudo 16 semanas, implicando em 112 dias após o transplantio (DAT).

Silva (2014) obteve valores médios de 43,10; 41,20; 46,00 e 44,00 cm em seu estudo, irrigando a pimenta tequila bode vermelha, com di- ferentes concentrações de efluente doméstico (100; 75; 50 e $25 \%$ ) diluído em água e observou que o maior valor foi $46,0 \mathrm{~cm}$, obtido quando a planta da pimenta foi irrigada com efluente doméstico concentrado (100\%), resultado similar ao verificado no estudo da mamoneira que alcançou 43,10 cm no T3 (irrigada com efluente tratado).

Os valores médios dos DC mostram que T3 e T4 estatisticamente foram considerados similares, ou seja, não houve diferença significativa, apresentando valores médios de 24,1 e 23,0 mm, respectivamente. Quando observados os T1 e T2, os valores médios que a cultura alcançou, após 112 DAT, foram 9,2 e 13,6 mm respectivamente, revelando que no T1, o DC da mamoneira obteve a menor espessura entre os quatro tratamentos. Entretanto, quando se observam os tratamentos T3 e T2, houve diferença significativa superior a 10,5 mm, mostrando que o T3 foi superior ao T2. Com isso, pode-se dizer que somente a irrigação da mamoneira com água não favoreceu um bom crescimento da cultura, que por ser da rede pública de abastecimento não oferece concentrações de nutrientes, como se espera de um sistema de abastecimento público de cidades.

De acordo com Silva (2015), em cultivo de eucalipto irrigado com esgoto doméstico, água e água+solo com NPK, não encontrou-se diferença significativa para o diâmetro do caule da cultura, comportamento contrário ao deste estudo. Entretanto, o comportamento contrário foi levantado por Freitas (2012), que encontrou superioridade no diâmetro do caule do girassol irrigado com esgoto doméstico tratado frente ao diâmetro do caule do girassol irrigado com água de poço: 15,23 mm e 13,30 mm, respectivamente. Os resultados obtidos neste estudo corroboram os resultados superiores encontrados da cultura quando irrigada com água residuárias. Estudando irrigação da mamoneira 
irrigada com água de diferentes, origens Paiva et al. (2012) e Nascimento et al. (2004) obtiveram desempenho estudando a influência do uso de efluente tratado em nível secundário na produção de mudas de pimentão e encontraram diferença significativa entre os tratamentos estudados. Eles relataram que o maior diâmetro caulinar foi verificado no tratamento utilizando $50 \%$ de esgoto tratado e $50 \%$ de água de abastecimento para irrigação da cultura.

Os diferentes tratamentos proporcionaram valores médios de NF, 6,5 e 7,4 unidades, para T1 e $\mathrm{T} 2$, respectivamente, considerando similares as outras variáveis. O T3 apresentou 16,7 unidades, considerado o melhor tratamento, seguido do T4, que ao final proporcionou 14,3 unidades. Com isso, os tratamentos demonstraram haver diferença superior de 2,4 unidades do T3 com relação ao T4 e, 10,2 unidades, também do T3, com relação ao $T 1$, sendo este considerado o tratamento menos eficaz para o desenvolvimento das folhas da mamoneira.

De maneira similar ao comportamento da mamoneira frente aos diferentes tipos de água para irrigação, Freitas (2012) observou o mesmo comportamento no estudo com girassol. Ele verificou um número aproximado de 25 folhas utilizando água de esgoto, diferenciando-se estatisticamente dos resultados obtidos com a água de poço, pois os valores médios situaramse em torno de 22 folhas por planta.

\section{a) Altura da Planta}

Os resultados da análise para AP para os 112 DAT estão apresentados na Figura 1. Pode-se observar que no decorrer do experimento houve um crescimento linear da planta; para essa variável estudada, esse crescimento se deu em decorrência de a cultura da mamona ainda não ter atingido a sua altura máxima.

O gráfico da Figura 1 mostra que existe uma alta correlação entre essa variável (AP) e o tempo do experimento, com coeficientes de determinação de R² de 0,9129 (T1); 0,9779 (T2); 0,991 (T3) e 0,977 (T4). Silva et al. (2014a) verificou comportamento similar ao verificado neste estudo com cultivar tequila bode vermelho irrigada com efluente doméstico em diferentes concentrações. Obteve-se coeficiente de determinação $R^{2}$ igual a 0,94. Estudando o crescimento do girassol sob irrigação com diferentes tipos de água e adubação, Freitas et al. (2012) observaram que na altura da planta o modelo que meIhor se ajustou foi o linear, com coeficientes de determinação $R^{2}$ igual a 0,8291 e 0,7024 para poço e efluente tratado, mostrando que houve um favorecimento hídrico da água de reúso diante da água oriunda do poço. Trabalhando com o crescimento das mudas de maracujazeiro amarelo irrigado com águas residuárias de lacticínio com concentrações crescentes, Silva (2014b) obteve crescimento linear, semelhante ao verificado neste estudo. 


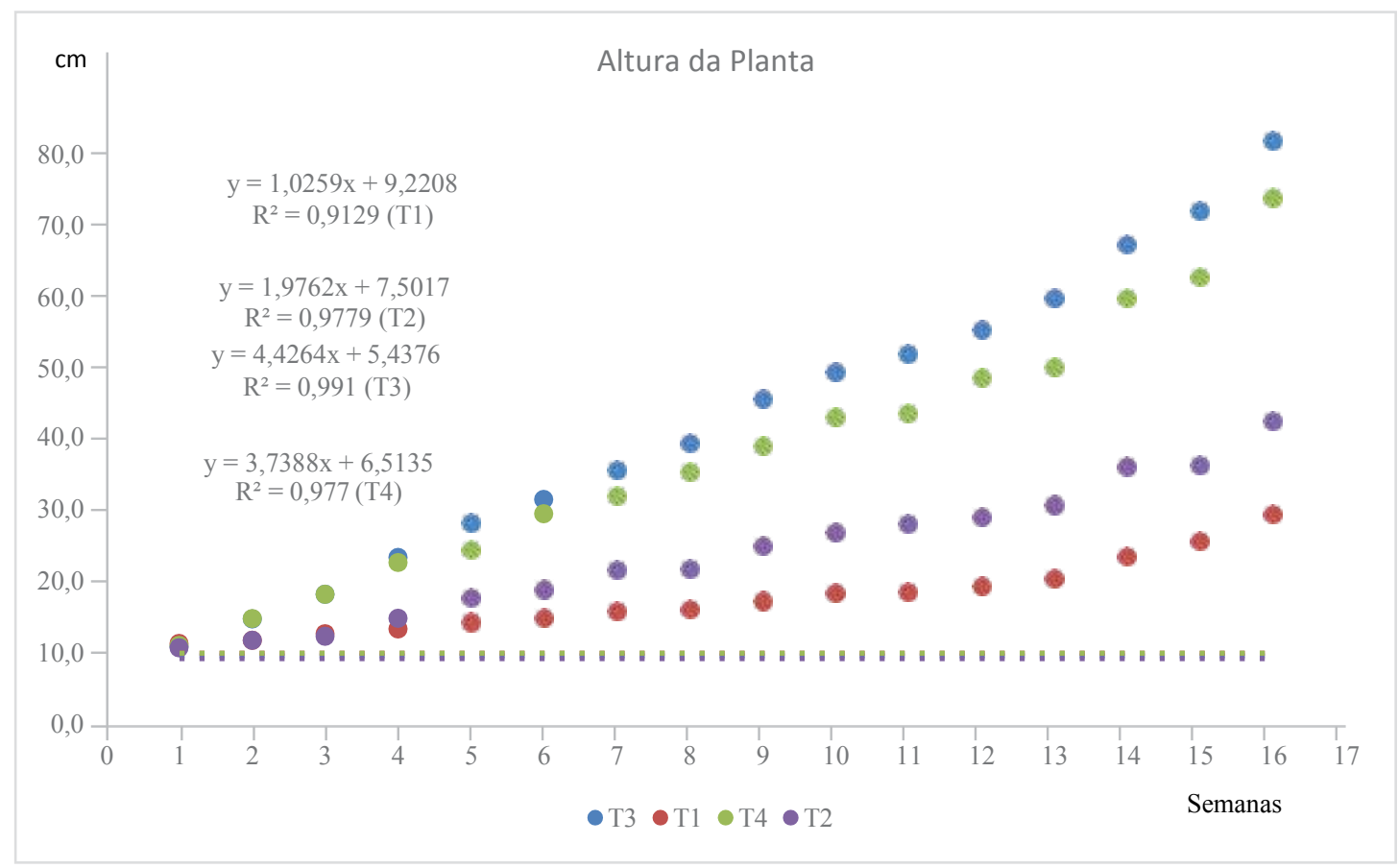

Figura 1: Desenvolvimento da altura da planta da mamoneira em função do tempo.

Os máximos e mínimos valores, respectivamente, da AP obtidos foram 29,17 e 11,5 cm no T1; 42,8 e $11,0 \mathrm{~cm}$ no T2; 82,0 e 11,2 cm no T3 e 74,0 e 11,3 cm no T4, para 7 a 112 DAT (início e final do experimento respectivamente). Esses valores correspondem a incrementos de $60,57 \%$ no $11 ; 74,30 \%$ no T2; $86,34 \%$ no T3 e $84,73 \%$ no T4, mostrando que houve crescimento da altura das plantas maior que $60 \%$ em todos os tratamentos. No entanto, o T3 apresentou melhor desempenho, revelando que o valor máximo atingido pela mamoneira, neste estudo, corresponde ao máximo valor entre os quatros tratamentos. Com isso, pode-se dizer que o bom crescimento da mamoneira pode estar associado à água de reúso, ou seja, águas residuárias domésticas tratadas, uma vez que é rica em nutrientes, principalmente nitrogênio e fósforo, como o utilizado neste estudo e apresentado na Tabela 2. Demonstra-se, assim, que os efluentes podem ser uma alternativa de irrigação para a mamoneira.

De acordo com Rodrigues et al. (2009), o crescimento da mamoneira é prejudicado quando ela é cultivada em solo com baixos teores de nutrientes, haja visto que essa planta demanda grande quantidade de nitrogênio para obter crescimento e produção viáveis. Com isso pode-se dizer que as concentrações de nitrogênio do efluente final das lagoas do Padre Palhano proporcionaram bons crescimentos da cultura utilizada neste estudo.

Segundo Leon e Cavallini (1999), quando ocorre irrigação das culturas com água de reúso tratado obtém-se maior produtividade se comparada à irrigação com água potável e fertilização química aplicada no solo, pelo fato de possuir grandes quantidades de nutrientes e alta concentração de matéria orgânica, que retém a umidade no solo e contribui para a fixação de nutrientes necessários à nutrição das plantas. Contudo, a análise estatística demonstrou que os valores mínimos de $\mathrm{AC}$ não diferiram entre si.

Uma similaridade dos valores encontrados nesta pesquisa foi verificada por Sampaio et al. (2011) em estudo, quando utilizaram águas residuárias para irrigar plantas de meloeiro, assim como Nobre et al. (2010), que obtiveram um bom desempenho da cultura no 
desenvolvimento da altura caulinar, irrigando com água de reúso, mostrando o benefício e recomendando o uso de efluentes domésticos como fonte viável des suprimento hídrico das culturas agrícolas.

\section{b) Diâmetro do Caule}

Os dados de DC da mamoneira em relação ao período de cultivo, correspondendo 112 DAT, para os diferentes tratamentos adotados neste estudo, revelaram que o modelo linear foi o que melhor se ajustou, com coeficientes de determinação $\mathrm{R}^{2}$ para T1, T2, T3 e T4 de 0,4367; 0,9824;0,9734 e 0,955, respectivamente, como mostra a Figura 2. Freitas (2012) também obteve crescimento linear do diâmetro do caule do girassol, com coeficientes de determinação de 0,859 e 0,8059 para água de poço e esgoto.

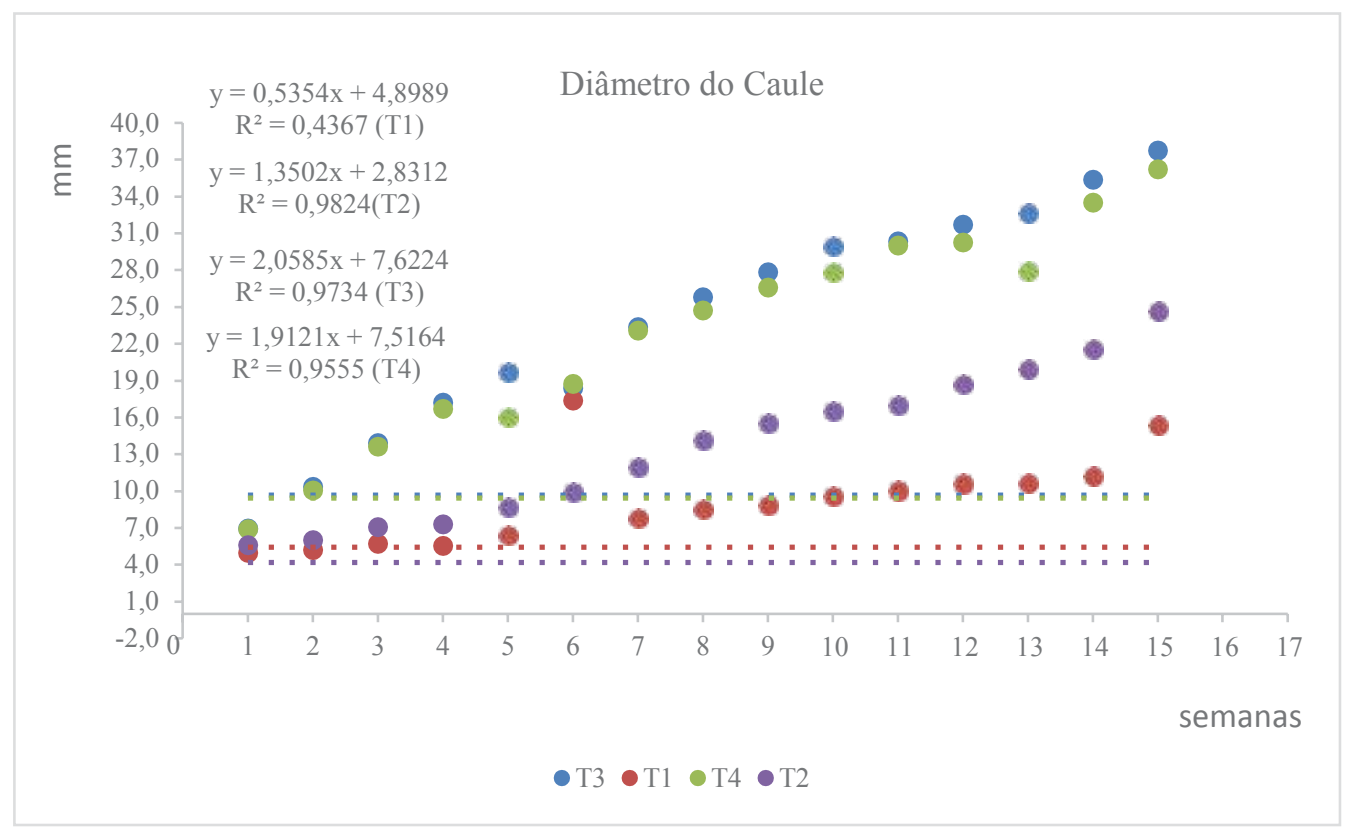

Figura 2: Desenvolvimento do diâmetro do caule da planta da mamoneira em função do tempo.

Segundo Freitas (2012), a superioridade, do diâmetro do caule do girassol foi alcançada quando ele foi irrigado com água de reúso (água residuária tratada) e pode estar associada aos nutrientes presentes nesse tipo de água destinado à irrigação. A partir dessa citação, pode-se associar que os bons resultados encontrados nesta pesquisa podem estar também relacionados ao efluente utilizado na irrigação dos T3 e T4, como apresentado na Tabela 2.

Pode-se visualizar na Figura 2 que o tratamento T3 se destacou entre os quatros tratamentos, apresentando valores variando entre o mínimo e máximo de 7,0 a $37,7 \mathrm{~mm}$ de $D C$ da mamo- neira após 112 DAT, implicando em um crescimento de $81,43 \%$. O segundo tratamento a se destacar foi o T4, que apresentou aos 7 DAT, início do experimento, valor de $6,9 \mathrm{~mm}$ e alcançou um valor máximo de $36,2 \mathrm{~mm}$ aos 112 DAT, mostrando que houve percentuais de crescimento de $80,93 \%$.

Azevedo et al. (2005) realizaram um estudo avaliando o crescimento do algodão irrigado com água de irrigação e águas residuárias tratadas e verificaram o percentual de crescimento de $65,98 \%$ quando irrigado com águas segundo tipo. $O$ resultado apresentado por estes autores foi inferior ao obtido neste estudo. 
$\mathrm{O}$ tratamento que mostrou menor desempenho foi o T2, com valor mínimo de DC de $5,6 \mathrm{~mm}$ e máximo de $15 \mathrm{~mm}$ ao final, implicando num crescimento de $62,67 \%$. No T1, aos 7 DAT, o valor de DC foi de 5,6 mm e 24,7 mm aos 1122 DAT, revelando que este tratamento obteve um incremento de $76,6 \%$.

Os resultados obtidos para o DC deste experimento corroboram o estudo realizado por Feitosa et al. (2015), quando estudaram as variáveis de crescimento, incluindo o diâmetro do caule do feijão caupi irrigado com concentrações diferentes de efluente doméstico e água salina, em que o melhor resultado foi obtido quando se irrigou a cultura com $100 \%$.

Analisando o crescimento e a produção de bagas da mamoneira irrigada com água residuária doméstica, Rodrigues et al. (2009) obtiveram crescimento de caule da mamoneira linear, porém com maior sensibilidade na fase inicial de crescimento, caso em que se deduz que plantas cultivadas sem restrição hídrica devem ser mais resistentes ao tombamento devido aos caules mais robustos. Segundo Ribeiro et al. (2011), as diferentes diluições da água residuária de esgoto doméstico aplicada na cultura da mamoneira não influenciaram o desenvolvimento do caule em seu estudo. Os resultados obtidos por esses autores foram contrários aos obtidos neste estudo, com exceção do diâmetro do caule.

\section{c) Números de folhas}

A Figura 3 apresenta o resultado do NF em relação ao tempo de cultivo da mamoneira diante dos diferentes tipos de tratamentos adotados. Verificou-se que o modelo polinomial de $2^{\circ}$ grau foi o que melhor se ajustou neste estudo.

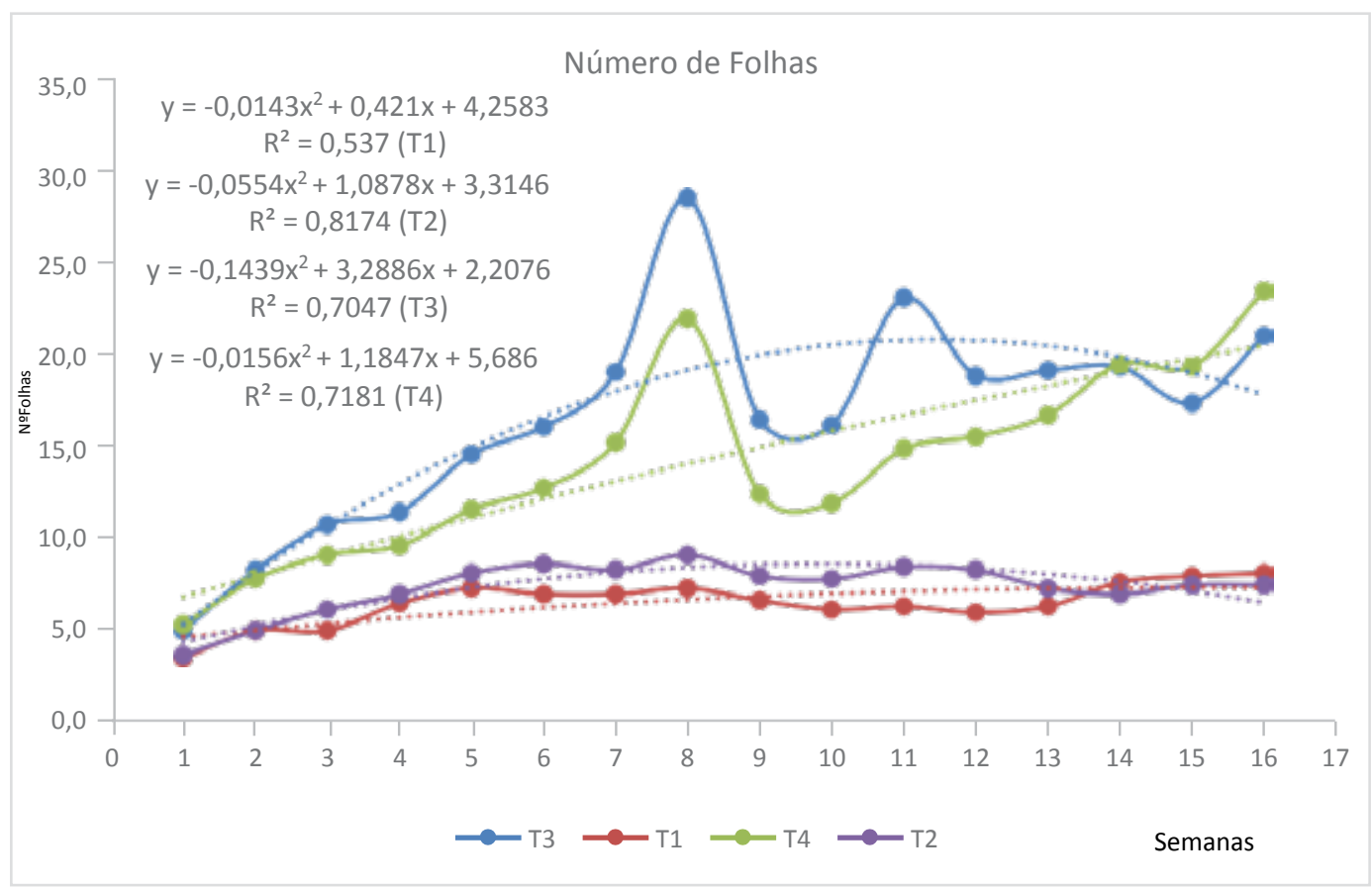

Figura 3: Crescimento inicial da variável números de folhas da planta da mamoneira em função do tempo. 
Segundo Oliveira (2009), a escolha de uma equação para representar o comportamento biológico de uma cultura deve levar em consideração os padrões estatísticos e fisiológicos, sem obsessões com detalhes de ordem racional, técnica, estatística ou de procedimentos experimental. Com base nessa citação, a função polinomial quadrática foi a que melhor se ajustou neste estudo e proporcionou as equações para cada tratamento, apresentada na Figura 3.

Os valores obtidos nos tratamentos aos 112 DAT mostraram T3 com 21 folhas em 11 semanas, superiores ao tratamento $\mathrm{T} 2$ com 9 folhas em 10 semanas, demonstrando que o efluente da lagoa de estabilização do Padre Palhano pode ser utilizada na irrigação da cultura da mamoneira, sendo sempre melhor que os tratamentos com água e adubo (T2) e água (T1), que obteve um número máximo de folhas 7,36 em 112 DAT, demostrando que o pós-tratamento do efluente tratado exerceu efeito quando ao desenvolvimento das folhas da cultura estudada.

De acordo com Freitas (2012), há diferenças significativas da cultura do girassol irrigada com água de diferentes origens, obtendo-se maior valor em unidades de folhas para as plantas irrigadas com efluente tratado quando comparadas com água de poço.

Quanto aos valores mínimos do NF aos 7 DAT da mamoneira, foram: 3,5 no T1; 3,7 no T2; 5,0 no T3 e 5,3 no T4, mostrando que durante o período estudado houve um incremento em todos os tratamentos de 56,$25 ; 62,25 ; 82,63$ e 77,64 \% para os tratamentos de $\mathrm{T} 1$ a T4 quando comparados aos valores do final do experimento 112 DAT.

Cuba et al. (2015) verificaram no experimento com alface hidropônico irrigado com efluente doméstico tratado e nutriente que as plantas apresentavam folhas amareladas no $5^{\circ}$ dia após o transplante, em decorrência da deficiência em nitrogênio. Esse resultado pode estar relacionado os valores diminutos do variável número de folhas para os T1 e T2 deste estudo, que foram irrigados com água de abastecimento em solo com e sem adubo, respectivamente, pois esses tratamentos não apresentavam nutrientes suficientes para promover o crescimento da cultura.

\section{d) Massa Seca da Planta}

Podem ser visualizados na Tabela 4 os valores médios para massa seca foliar (MSF), massa seca do caule (MSC) e massa seca da raiz (MSR), mostrando que as plantas irrigadas com o tipo de água destinado a T3 foram superiores, de acordo com o teste Tukey, a 5\% de probabilidade, aos demais para todas as variáveis

Tabela 4: Valores médios da massa seca foliar, massa seca da caule e massa seca da raiz em função dos tipos de água utilizada nos quatro tratamentos.

\begin{tabular}{|c|c|c|c|} 
Tratamento & $\begin{array}{c}\text { MSF } \\
\text { (g/planta) }\end{array}$ & $\begin{array}{c}\text { MSC } \\
\text { (g/planta) }\end{array}$ & $\begin{array}{c}\text { MSR } \\
\text { (g/planta) }\end{array}$ \\
\hline T1 & $12,03 \mathrm{c}$ & $13,85 \mathrm{~d}$ & $14,22 \mathrm{c}$ \\
\hline T2 & $34,44 \mathrm{~b}$ & $44,67 \mathrm{c}$ & $45,46 \mathrm{~b}$ \\
\hline T3 & $50,17 \mathrm{a}$ & $126,46 \mathrm{a}$ & $133,7 \mathrm{a}$ \\
\hline T4 & $42,25 \mathrm{ab}$ & $96,98 \mathrm{~b}$ & $120,84 \mathrm{a}$ \\
\hline CV(\%) & 23,76 & 21,81 & 16,8 \\
\hline DMS & 13,34 & 24,85 & 21,33 \\
\hline
\end{tabular}

Os valores médios obtidos para MSF variaram de 34,44 a 50,17 $\mathrm{g}$ entre os tratamentos adotados neste estudo. Esses valores mostram que houve diferença significativa entre T3 e T1; T3 e T2, em que T3 foi superior a 76,02 e 31,43\% a T1 e T2, respectivamente. Entretanto não houve diferença significativa entre T3 e T4, mostrando que os efluentes tratados e pós-tratados influenciam de maneira similar a matéria seca das folhas da mamoneira.

Feitosa et al. (2015), avaliando o crescimento do feijão irrigado com diferentes concentrações de efluentes tratado e salino, obtiveram comportamento similar ao deste estudo; para MSF, houve 
um incremento de $100 \%$ quando a irrigação da cultura foi com o efluente.

Para a MSC, os resultados mostram que houve diferença significativa do T3 relacionado aos demais tratamentos, implicando em crescimentos percentuais de 89,$05 ; 64,68$ e $23,31 \%$ para T1, T2 e T3 respectivamente, mostrando que para o desenvolvimento do caule o T3 foi superior no período estudado, 112 DAT.

Em estudo realizado com produção de mudas de abóbora e jiló, Lima (2012) obteve os maiores resultados para MSC quando as plantas foram totalmente irrigadas com água residuária, obtendo percentuais de $100 \%$ frente aos demais tratamentos.

Quando se analisam os resultados de MSR, a Tabela 4 mostra não haver diferença significativa entre T3 e T4 para 112 DAT; porém, quando comparado com T1 e T2, ficam evidenciadas as diferenças significativas, implicando em percentuais de 83,23 e $62,38 \%$ quando comparados com os tratamentos anteriormente comentados.

Os fatores ambientais podem afetar o crescimento e a distribuição das raízes. Entre eles, destacam-se: fertilidade, porosidade, oxigênio, dióxido de carbono, $\mathrm{pH}$, temperatura, água, competição entre plantas e desfolhamento (MITCHELL e TELL, 1977). Dentre eles, a adubação é fundamental para o bom crescimento do sistema radicular, pois com adubação há nutrientes disponíveis que interferem diretamente no crescimento e na morfologia do sistema radicular. Portanto, pode-se associar que os valores obtidos da MSR no T3 e T4 foram decorrentes da adubação natural que ocorreu com a fertirrigação da mamoneira.

\section{CONCLUSÕES}

Após os resultados obtidos neste estudo, pode-se concluir que para todas as variáveis de morfofisiológica da mamoneira (Altura da planta, Diâmetro do Caule e Número de Folhas) houve supe- rioridade quando as plantas foram irrigadas com efluentes 1 e 2. Outra conclusão está relacionada com a massa seca das folhas, dos caules e das raízes, dos tratamentos adotados. O T3 foi superior, mostrando que o efluente das lagoas de estabilização pode ser utilizado na irrigação da cultura da mamoneira, principalmente em regiões assoladas pela escassez hídrica, a exemplo da cidade de Sobral, além de contribuir para a preservação do meio ambiente e diminuir a quantidade de efluentes lançados em corpos receptores.

O reúso de efluentes domésticos na irrigação da mamoneira é uma alternativa viável, por possuir nutrientes disponíveis em quantidades necessárias ao desenvolvimento da cultura, como obtido neste estudo para todas as variáveis analisadas. Além disso, pode minimizar o uso de nutrientes minerais.

\section{REFERÊNCIAS BIBLIOGRÁFICAS}

ANJOS E SILVA, D. dos; CASAGRANDE, J. G.; MAGNANI, M. Sistema de Produção da Mamona. Embrapa Clima Temperado. ISSN 1806-9207 - Versão Eletrônica. 2007.

APHA. AWWA. WPCF. Standard Methods for The Examination of Water And Wastewater. 15 ed. Washington, DC. American Public Health Association. American Water Works Association, Water Pollution Control Federation, 2005.

AYERS, R. S.; WESTCOT, D. W, A qualidade da água na agricultura. [Campina Grande]: UFPB, 1991. 218p. (Estudos FAO: Irrigação e Drenagem; 29)

AYERS, R. S.; WESTCOT, D. W. A qualidade da água na agricultura, tradução de H. R. Gheyi, J. F. de Medeiros F. A. V. Damasceno. Campina Grande: UFPB. 1999.

AZEVEDO, D.M. de; NÓBREGA, L.B. da; LIMA, E.F.; BATISTA, F.A.S.; BELTRÃO, N.E. de M. Manejo Cultural. In: AZEVEDO, D.M.P. de.; LIMA, E.F. (Eds.). $O$ agronegócio da mamona no Brasil. Brasília: Embrapa Informação Tecnológica, p.121-160, 2001.

AZEVEDO, M. R. de Q.; BELTRÃO, N. E. de M.; Konig, A.; AZEVEDO, C. A. V. de;PORDEUS, R. V.; TAVARES, T. de L. Análise comparativa da produção do algodoeiro herbáceo irrigado com água residuária e água de abastecimento e adubação nitrogenada. In: Congresso Brasileiro de Algodão, 5, Salvador, 2005. Anais.

BLUM, J.R.C. Critérios e padrões de qualidade da água. In: MANCUSO, P.C.S. \& SANTOS, H.F. ed. Reúso de água. São Paulo: Manole, 2003. p. $125-174$. 
CARVALHO, B. C. L., (2005). Manual do cultivo da mamona. Salvador: EDBA 65p.

CHIERICE, G. O.; CLARO NETO, S. Aplicação industrial do óleo. In: AZEVEDO, D. M. P.; LIMA, E. F. (Ed.) O Agronegócio da mamona no Brasil. Brasília: Embrapa Informação Tecnológica, p. 89- 120, 2001.

CONAMA. Conselho Nacional do Meio Ambiente. Resolução n³12 de 10 de Dezembro de 2002.

CUBA, R.S.; CARMO, J.R.; BASTOS, R.G.; SOUZA, C.F. Potencial de aplicação de esgoto doméstico tratado como fonte de nutrientes e água no cultivo hidropônico de alface. Revista Ambiente \& Água, v.10, n.3, p.574-586, 2015.

EMBRAPA ALGODÃO - Empresa Brasileira de Pesquisa Agropecuária. Disponível em: http://www.cnpa.embrapa.br/produtos/ mamona/zoneamento_pb.pdf. Acesso em: 11/02/2008

EMBRAPA MAMONA - Empresa Brasileira de Pesquisa Agropecuária. Disponível em: http://www.cnpa.embrapa.br/produtos/mamona/zoneamento_pb.pdf .Acesso em: 11 de dezembro de 2008.

FAO/ UNESCO - FOOD AND AGRICULTURE ORGANIZATION OFTHE UNITED NATIONS. Irrigation, drainage and salinity: an international source book. London, Hutchinson/FAO/Unesco, 1973.

FEIGIN, A., RAVINA I. et al. Irrigation with treated Sewage Effluent: management for environmental protection. Berlim: Springer Verlag, v.17. 224 p, 1991.

FEITOSA, S. O.; SILVA, S.L.; FEITOSA, H. O.; CARVALHO, C. M.; FEITOSA, E. O. Crescimento do feijão caupi irrigado com diferentes concentrações efluente tratado e água salina. Revista AGROTEC Universidade Federal da Paraíba, v. 36, n. 1, p. 146-155, 2015

FREITAS, C. A. S. de; SILVA, A. R. A da; BEZERRA, F. M. L.; ANDRADE, R. R. de;MOTA, F. S. B; AQUINO, B. F. de. Crescimento da cultura do girassol irrigado com diferentes tipos de água e adubação nitrogenada. Revista Brasileira de Engenharia Agrícola e Ambiental. V.10. n.10. 2012. p. 1031-1039.

LEON, S. G.; CAVALLINI, J. M. Tratamento e uso de águas residuárias. Campina Grande; UFPB, 110 p, 1999.

LIMA, G. G. de; RIBEIRO, S. C. Geomorfologia e paisagem do município de Juazeiro do Norte/CE: Relações entre a natureza semiárida e os impactos antrópicos. Revista Geonorte, ed. Especial. V.2. n.4 p. 520-530, 2012

LIMA, V. I. A.; Alves, S. M. C., Neto, M. F.; Oliveira, R. B. de. Reutilização de água residuária na produção de mudas de abóbora e jiló. ENCICLOPÉDIA BIOSFERA, vol.7, N.13, 2011, p. 949-958

MACHADO, E.C.; PEREIRA, A.R.; FAHL, J.I.; ARRUDA, H.V.; CIONE, J. Índices Biométricos de duas variedades de cana-de-açúcar. Pesquisa Agropecuária Brasileira, Brasília, v.17, n.9, p.13231329, 1982.
MAGALHÃES, A.C.N. Análise quantitativa do crescimento. In: FERRI, M.G. (Ed.). Fisiologia vegetal. Edusp. v.1, p.331-341, 1979.

MINISTÉRIO DO MEIO AMBIENTE: Secretaria de Recursos Hídricos. Disponível em: htpp://meioambiente.gov.br.Acessado em: 24 de janeiro de 2016.

MITCHELL, W. H. \& TELL, M.R. Writer-annual cover crops for no tillage corn production. Agronomy Journal, 69:569-573, 1977

PAIVA, L. A. L.de; ALVES, S. M. C.; FERREIRA NETOS, M.; OLIVEIRA, J. F. de.Influência da Aplicação de esgoto doméstico secundário na produção de mudas de pimenta malagueta e pimentão. Enciclopédia Biosfera. Goiânia. V.8, n. 15. p. 1058-1066, 2012.

NASCIMENTO, M. B. H. et al. Utilização de água residuária e biossólido na cultura da mamona: crescimento e desenvolvimento. In: Congresso brasileiro de mamona, 1. 2004, Campina Grande-PB. Anais, Campina Grande: Embrapa. 1 CDROM.

NOBRE, R. G.; Gheyi, H. R.; SOARES, F. A. L.; Andrade, L. O. de; NASCIMENTO, E. C. S. Produção do girassol sob diferentes lâminas com efluentes domésticos e adubação orgânica. Revista Brasileira de Engenharia Agrícola e Ambiental, v.14, p.747-754, 2010

NUVOLARI; COSTA. Reúso da água: conceitos, teorias e práticas. São Paulo: Blucher, 2003.

NUVOLARI, A. Esgoto Sanitário: coleta, transporte, tratamento e reúso Agrícola. São Paulo: Blucher, 2008.

OLIVEIRA, S. J. C. Componentes de crescimento do pinhão manso (Jatropha curcas L.) em função da adubação mineral e da poda. Tese (Doutorado em agronomia). UFPB. Areia, 2009. 126p.

REICHARDT, K. Capacidade de campo. Revista Brasileira de Ciência do Solo, 12:211-216, 1988.

RIBEIRO, M. C. de F.; ROCHA, F. A.; SANTOS, A. C. dos; SILVA, J. O. da; PEIXOTO

M F. S. P. e PAZ, V. P. da S. Crescimento e produtividade da mamoneira irrigada com diferentes diluições de esgoto doméstico tratado. Revista Brasileira de Engenharia Agrícola e Ambiental v.16, n.6, p.639-646, 2012.

RICHARDS, L.A. Methods of measuring soil moisture tension. Soil Science 68:95-112, 1949.

RICHARDS, L. A. Diagnostics and improvement of salinity and alkali soil. Washington, D.C: United States Salinity Laboratory, 1954. 160p (United States Department of Agriculture. Handbook, 60).

RODRIGUES, L N.; Nery, A. R.; FERNANDES, P. D.; BELTRÃO, N. E. M.; e GHEYI, H R. Crescimento e produção de bagas da mamoneira irrigada com água residuária doméstica. Revista Brasileira de Engenharia Agrícola e Ambiental. v.13, (Suplemento), p.825-835, 2009.

RIBEIRO, MC. de F.; ROCHA, F. A.; SANTOS, A C. dos; SILVA, J. O. da; PEIXOTO, M. de F. S. P. e PAZ, V. P. da S. Crescimento e produtivi- 
dade da mamoneira irrigada com diferentes diluições de esgoto doméstico tratado. Revista Brasileira de Engenharia Agrícola e Ambiental.v.16, n.6, p.639-646, 2012.

SILVA, J.R; GAVAZZA, S.; FLORENCIO, L; NASCIMENTO, C. W. A e KATO, M. T. Cultivo de mudas de eucalipto irrigadas com esgoto doméstico tratado. Engenharia Sanitária e Ambiental. v. 20. n.2. Abr/Jun. p.323-330, 2015.

SILVA, F. A. S.; AZEVEDO, C. A. V. Principal componentes analysis in the software assistat-statisitical attendence. In: World Congress on Computers in Agriculture, 7. Reno- NV-USA. American Society of Agriculture ande Biological Engineers. 2009.

SILVA, L. L.; CARVALHO, C. M.; SOUZA, R. P. F.; FEITOSA, H. O.; FEITOSA, S. O. e GOMES FILHO, R. R., Utilização de efluentes domésticos no crescimento da pimenta (Caspsicum chinense), cultiva tequila bode vermelha. Revista AGROTEC. V.35. n1.p121- 133, 2014 a.

SILVA, E. A. da; R. J. D; SILVA, F.O. R.; SOARES, F. M.; SANTOS, V. A. dos e FERREIRAS, A. E. Adição de água residuária de laticínio em substrato para produção de mudas de maracujazeiro 'amarelo'. Revista Agrarian. v.7, n.23, p.49-59, 2014b.
SILVA, L. V. B.; LIMA, V.L.A.; SILVA, V. N. B.; SOFIATTI, V.; PEREIRA, T. L. P. Torta de mamona residual e irrigação com efluente sore crescimento e produção do algodoeiro herbáceo. Revista Brasileira de Engenharia Agrícola e Ambiental. V. 17, n. 12, p. 12641270, 2014.

SOUZA. A. M. S.; CARVALHO. R. S.; SANTOS, H. B.; MACHADO, C. A.; DANTAS, L. A; FACCIOLI, G. G. Qualidade da Água Deso e Água Residuária Proveniente do Sistema de Lagoas de Estabilização. Revista Brasileira de Agricultura Irrigada. v.9. n.1. p. 24-31, 2015.

TELLES, D. D.; COSTA, R. P. Reúso de água: Conceitos, teorias e práticas. $2^{\circ}$ ed. São Paulo. 408p, 2010.

VON SPERLING, M. Princípios do tratamento biológico de águas residuárias, V.3 - Lagoas de Estabilização. Departamento de Engenharia Sanitária e Ambiental; Universidade Federal de Minas Gerais. Belo Horizonte, MG. 134p, 1996.

VON SPERLING, M. Introdução à qualidade e ao tratamento de esgotos. $3^{\mathrm{a}}$ ed. Belo Horizonte: Departamento de Engenharia Sanitária e Ambiental; Universidade Federal de Minas Gerais; 2005. 